\title{
Derivation of pb(II)-sensing Escherichia coli cell-based biosensors from arsenic responsive genetic systems
}

Yejin Lee ${ }^{1}$, Yangwon Jeon ${ }^{1}$, Guepil Jang ${ }^{2}$ and Youngdae Yoon ${ }^{1 *}$ (D)

\begin{abstract}
Heavy metal-responsive operons were used for the generation of Escherichia coli cell-based biosensors. The selectivity and specificity of the biosensors were determined based on the interaction between heavy metals and regulatory proteins; thereby, the modulating target selectivity of biosensors could be achieved by changing target sensing properties of regulatory proteins. The results of this study demonstrated that $\mathrm{Pb}$ (II)-sensing biosensors could be generated from an arsenic-responsive genetic system, which was originally used for arsenic-sensing biosensors. The amino acids around to As(III)-binding sites of ArsR were mutated and cysteine residues were relocated to modulate the metal selectivity. In addition, genes encoding metal ion-translocating P-type ATPases, such as copA and zntA, were deleted to enhance the specificity by increasing the intercellular levels of divalent metal ions. Based on the results, channel protein deleted E. coli cells harboring a pair of recombinant genes, engineered ArsR and arsAp::egfp, showed enhanced responses upon $\mathrm{Pb}$ exposure and could be used to quantify the amount of $\mathrm{Pb}(\mathrm{II})$ in artificially contaminated water and plants grown in media containing $\mathrm{Pb}(\mathrm{II})$. Although we focused on generating $\mathrm{Pb}$ (II)-specific biosensors in this study, the proposed strategy has a great potential for the generation of diverse heavy metal-sensing biosensors and risk assessment of heavy metals in environmental samples as well as in plants.
\end{abstract}

Keywords: Bacterial cell-based biosensors, Lead, ArsR, Protein engineering, Heavy metals

\section{Introduction}

Environmental pollutants including diverse organic chemicals, plastics, and heavy metal(loid)s produced in industrial processes are released into environmental systems as final reservoirs and are considered as potential threats to human health. Therefore, diverse pollutants are strictly regulated and regularly monitored to assess their risks. The monitoring and quantification of pollutants are typically carried out using analytical instruments. Although analytical instrument-based monitoring is very accurate and precise, it is expensive and requires time-consuming pretreatment processes

\footnotetext{
*Correspondence: yyoon21@gmail.com

1 Department of Environmental Health Science, Konkuk University, 05029 Seoul, Republic of Korea

Full list of author information is available at the end of the article
}

because of the complex nature of the environmental matter. Furthermore, the risks of pollutants tend to be overestimated because the total amounts are measured instead of biologically active amounts. Therefore, alternative quantification methods must be established. Several quantification methods have been reported, which are based on different scientific technologies including biological, electrochemical, chemical, and nanotechnologies (Baruah and Dutta 2009; Hanrahan et al. 2004; Simonds et al. 1994; Zhou et al. 2017).

Among the new sensing techniques, bacterial cellbased biosensors have been actively investigated during the past few decades (Belkin 2003; Tecon and Van der Meer 2008). Most bacterial cell-based biosensors are based on stress-responsive genetic systems. For heavy metal sensing, metal-responsive genetic systems are used. Briefly, the recombinant genes constructed by 
fusing promoter regions and reporter genes encoding enzymes and fluorescent proteins are introduced to bacterial cells. The expression of the reporter genes is controlled by regulatory proteins in stress-responsive genetic systems. The level of interaction between the regulatory proteins and ligands results in the expression of reporter genes. Consequently, the ligands can be indirectly quantified based on the expression levels of the reporter genes. These biosensors are advantageous because they involve less expensive and less time-consuming processes; they can be used to quantify heavy metals in diverse matrixes compared with analytic instruments and to measure the biologically active amount of heavy metals, that is, the so-called bioavailability (Hynninen and Virta 2009; Yoon et al. 2016c). Although they have several advantages and huge potentials as alternative analytic tools, biosensors have not been widely used in practical applications. The reasons might include the lack of specificity and sensitivity in comparison with analytical instruments and the limited number of genetic systems compared with the number of heavy metals. In fact, stress-responsive genetic systems in living organisms generally have a broad specificity and sensitivity to ligands to efficiently respond because it could be attritional to possess all genetic systems toward stresses. Therefore, many research groups are investigating bacterial cell-based biosensors and make efforts to enhance the target specificity and selectivity based on genetic and protein engineering (Cerminati et al. 2015; Lee et al. 2020; Yagur-Kroll and Belkin 2014).

Considering the principles of bacterial cell-based biosensors, the specificity and selectivity depend on the level of the interaction between targets and regulatory proteins. Thus, the performance of biosensors can be enhanced by modulating regulatory proteins. Therefore, many researchers are focusing on the generation of new target-sensing biosensors and the enhancement of the sensing performances based on the genetic engineering of regulatory proteins in currently available biosensors such as GolS, ZntR, and ArsR (Cerminati et al. 2011; Kang et al. 2018; Lee et al. 2020). In addition, it has been reported that the heavy metal specificity/sensitivity of bacterial cell-based biosensors can be enhanced by interfering with the metal homeostasis in bacteria (Ibáñez et al. 2015; Yoon et al. 2018). The sensitivity to targets increases because deleting the genes related to the metal export results in the accumulation of target metal ions in bacterial cells.

In this study, a new strategy to generate new metalsensing biosensors based on the above-mentioned procedure was introduced. We manipulated the target selectivity of ArsR, a regulatory protein controlling the arsenic responsive operon, by shifting it from As(III) to $\mathrm{Pb}(\mathrm{II})$. We also enhanced the sensitivity by deleting metal-exporting channels, such as CopA and ZntA, which are known to export metal ions from Escherichia coli $(E$. coli). The applicability of the new $\mathrm{Pb}(\mathrm{II})$-sensing biosensors was evaluated by measuring the $\mathrm{Pb}$ (II) concentration in artificially contaminated water and plants grown in $\mathrm{Pb}(\mathrm{II})$-bearing media.

\section{Materials and methods \\ Materials}

All heavy metal(loid)s tested in this study, including $\mathrm{AsCl}_{3}, \mathrm{CdCl}_{2}, \mathrm{NiCl}_{2}, \mathrm{HgCl}_{2}, \mathrm{PbSO}_{4}, \mathrm{ZnCl}_{2}$, and $\mathrm{CuSO}_{4}$, were purchased from Sigma-Aldrich (St. Louis, MO, USA). Metal(loid) solutions were prepared as $1 \mathrm{mM}$ stock solutions by dissolving each metal(loid) salt in distilled water and ethanol. HotStar Taq and Pfu Turbo DNA polymerases were used for the DNA amplification and sitedirected mutagenesis, respectively. Both were purchased from Qiagen. Restriction enzymes and T4 DNA ligase were purchased from Takara Korea Biomedical (Seoul, Korea). The primers used in this study were synthesized and purchased from Macrogen (Daejeon, Korea). A Quick \& Easy E. coli Gene Deletion Kit (Gene Bridges, Heidelberg, Germany) was used to generate endogenous gene-deficient $E$. coli strains.

\section{Generation of $E$. coli cell-based biosensors}

The arsR-encoding ArsR, a regulatory protein was amplified from the genomic DNA of E. coli by PCR. The gene was cloned into a pCDFDuet vector (Novagen) with BamHI/XhoI restriction enzyme sites. Mutations were introduced to ArsR by the site-directed mutagenesis using Pfu Turbo and the corresponding primers; the amino acid sequences of all engineered ArsR were confirmed by DNA sequencing. The plasmid-carrying

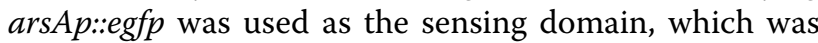
constructed in our previous study (Yoon et al. 2016b). Gene deletion in E. coli was performed with the Quick \& Easy E. coli Gene Deletion Kit following the manufacturer's instructions, with minor modifications. Genes such as $z n t A$ and $\operatorname{cop} A$, encoding $\mathrm{Zn}(\mathrm{II})$ - and $\mathrm{Cu}(\mathrm{I})$-translocating P-type ATPases, were replaced by kanamycin resistance genes, and the gene deletions were verified by PCR. The E. coli cell-based biosensors were generated by introducing a pair of plasmid-carrying $\operatorname{ars} R$ and $\operatorname{arsAp}:$ egfp to wild-type $E$. coli (BL21) and gene deficient strains.

\section{Genetic engineering of ArsR}

The metal selectivity of $E$. coli cell-based biosensors changes upon the deletion of genes related to the metal homeostasis of the host cells. In addition, it has been reported that the selectivity of biosensors can be modulated by the genetic engineering of regulatory 
proteins (Lee et al. 2020; Yoon et al. 2018). The selectivity of $E$. coli cell-based biosensors based on an arsoperon system was determined based on the selectivity of ArsR. The results show that the selectivity of biosensors can be modulated by shifting the selectivity of ArsR. As previously reported, the arsenic-binding site of ArsR is a short helix region, amino acid numbers 30 to 39 sequenced as ELCVCDLCTA, and three cysteines are known to be the key residues for As recognition (Busenlehner et al. 2003; Shi et al. 1994). To evaluate the effects of cysteine residues, Cys 32, 34 and 37 were initially mutated to Ser, and then additional mutations were introduced. Briefly, deleted cysteines were relocated to Leu36, Thr38 or Ala39, and cysteines were added to Glu30 or Val33. In summary, ArsR W1-6 and YJ1-21 were generated and tested the metal selectivities along with WT ArsR. The amino acid sequences and the positions of cysteines for engineered ArsRs were listed in Table 1.

\section{Biosensor assay}

The heavy metal(loid) selectivity of the biosensors to heavy metal(loid)s was tested using the following experimental conditions. The biosensor cells were grown overnight and then inoculated into fresh media. When the optical density of cells reached $0.4\left(\mathrm{OD}_{600}\right)$, the cells were exposed to $5 \mu \mathrm{M}$ of diverse heavy metal(loid) ions. After an exposure of $1 \mathrm{~h}$, the expression levels of eGFP were measured using a fluorescence spectrophotometer (FC2, Sinco, Korea) and excitation and emission wavelengths of $480 \mathrm{~nm}$ and $510 \mathrm{~nm}$, respectively. Cells without heavy metal(loid) exposure were considered to be control samples, and the expression level of eGFP was represented as induction coefficient values (intensity of biosensors with metal exposure/intensity of the control). The $E$. coli cell-based sensors displaying target metal responses were further investigated to evaluate the metal specificity. To optimize the experimental conditions, the metal exposure, exposure duration, and concentration of heavy

Table 1 List of engineered ArsR and metal(loid)s selectivity upon host E. coli strains

\begin{tabular}{|c|c|c|c|c|c|c|c|}
\hline \multirow[t]{2}{*}{ No } & \multirow[t]{2}{*}{ Name } & \multirow{2}{*}{$\begin{array}{l}\text { Amino acid } \\
\text { sequence (no. } \\
30-40 \text { ) }\end{array}$} & \multirow[t]{2}{*}{ Cysteine location } & \multicolumn{3}{|c|}{ Order of responding strength } & \multirow[t]{2}{*}{ References } \\
\hline & & & & E. coli-arsR & E. coli-arsR/copA & E. coli-arsR/zntA & \\
\hline 1 & WT & ELCVCDLCTA & Cys-32,34,37 & $\operatorname{As}(9.8)$ & $\operatorname{As}(8.46)$ & As (7.38)>Pb (1.85) & Kim et al. (2020) \\
\hline 2 & W4 & ELCVCDLSTTC & Cys-32,34,39 & $\operatorname{As}(5.7)>>C d(1.95)$ & $\operatorname{As}(3.64)$ & $\mathrm{Pb}(3.03)>\operatorname{As}(2.31)>\mathrm{Cd}(1.73)$ & Lee et al. (2020) \\
\hline 3 & W6 & ELCVCDCSTA & Cys-32,34,36 & $\operatorname{As}(5.08)$ & $\operatorname{As}(4.23)$ & $\mathrm{Pb}(4.05)>\mathrm{Cd}(2.56)>\mathrm{As}(1.79)$ & Lee et al. (2020) \\
\hline 4 & YJ6 & $\underline{\mathbf{C}} \mathrm{L} \vee \vee C D L \underline{S} T \underline{\mathbf{C}}$ & Cys-30,32,34,39 & $\operatorname{As}(3.34)$ & $\operatorname{As}(1.58)$ & $\mathrm{Pb}(2.31)>\operatorname{As}(1.77)>\mathrm{Cd}(1.53)$ & This study \\
\hline 5 & YJ20 & ELCVCDLCT $\underline{\mathbf{C}}$ & Cys-32,34,37,39 & $\operatorname{As}(4.54)$ & $\operatorname{As}(2.43)$ & As (2.71)>Pb (2.31)>Cd(1.3) & This study \\
\hline 6 & W2 & ELCVCDLSTTA & Cys-32,34 & $\operatorname{As}(11.34)$ & $\operatorname{As}(10.46)$ & $\operatorname{As}(9.98)>>P b(2.06)$ & Lee et al. (2020) \\
\hline 7 & W3 & ELCVCDLSCA & Cys-32,34,38 & $\operatorname{As}(18.40)$ & $\operatorname{As}(8.87)$ & $\operatorname{As}(9.13)>>P b(1.67)>C d(1.60)$ & Lee et al. (2020) \\
\hline 8 & YJ2 & $\underline{\mathbf{C}} L C \vee C D L \underline{S} T A$ & Cys-30,32,34 & $\operatorname{As}(3.06)$ & $\operatorname{As}(2.21)$ & As $(2.50)>\mathrm{Pb}(1.57)$ & This study \\
\hline 9 & YJ1 & $\underline{\mathbf{C}} \underline{\underline{S}} \mathbf{V} \mathrm{CD} L \mathbf{C T A}$ & Cys-30,34,37 & $-\ddagger$ & - & - & This study \\
\hline 10 & YJ4 & ECSVVDLSTT $\underline{\mathbf{C}}$ & Cys-31,34,39 & - & - & - & This study \\
\hline 11 & YJ5 & $\underline{\mathbf{C}} \underline{\mathrm{S}} \underline{\mathrm{V}} \mathrm{CD} L \underline{S} T \underline{\mathrm{C}}$ & Cys-30,34,39 & - & - & - & This study \\
\hline 12 & YJ11 & $\mathrm{ELCV} \underline{\mathrm{SC}} \underline{\mathrm{ST}} \underline{\mathrm{C}}$ & Cys-32,35,39 & - & - & - & This study \\
\hline 13 & YJ14 & ELCCSDLSCA & Cys-32,33,38 & - & - & - & This study \\
\hline 14 & YJ15 & ELCCSDLSTC & Cys-32,33,39 & - & - & - & This study \\
\hline 15 & YJ19 & ELCV $\underline{S} D L C T \underline{C}$ & Cys-32,37,39 & - & - & - & This study \\
\hline 16 & YJ21 & ELSIVCDLSTC $\underline{C}$ & Cys-34,39 & - & - & - & This study \\
\hline 17 & YJ3 & $\underline{\mathbf{C}}\llcorner\mathbf{C} \vee C D \perp C T A$ & Cys-30,32,34,37 & $\operatorname{As}(4.26)$ & $\operatorname{As}(2.16)$ & $\operatorname{As}(2.40)$ & This study \\
\hline 18 & YJ7 & $\underline{\mathbf{C}} \underline{\mathrm{S}} \underline{\mathrm{V}} \mathrm{CD} \underline{\mathrm{CS}} \mathrm{TA}$ & Cys-30,34,36 & - & - & - & This study \\
\hline 19 & YJ8 & $\underline{\mathbf{C}} \mathrm{LC} \vee \mathrm{CD} \underline{\mathrm{CS}} \mathrm{S} A$ & Cys-30,32,34,36 & - & - & - & This study \\
\hline 20 & YJ12 & ELCCCDLSCA & Cys-32,33,34,38 & As (1.50) & - & $\mathrm{Cd}(1.60)>P b(1.38)$ & This study \\
\hline 21 & YJ13 & ELCCCDLST $\underline{C}$ & Cys-32,33,34,39 & As (2.41) & $\operatorname{As}(1.61)$ & $\mathrm{Pb}(1.43)>\operatorname{As}(1.28)>\mathrm{Cd}(1.26)$ & This study \\
\hline 22 & YJ16 & ELSCCDLSCA & Cys-33,34,38 & - & - & - & This study \\
\hline 23 & YJ17 & ELSSCDLSTC & Cys-33,34,39 & - & - & - & This study \\
\hline 24 & YJ18 & ELCCCDLSTA & Cys-32,33,34 & - & - & - & This study \\
\hline
\end{tabular}

+ Cysteines in amino acid sequences were indicated as bold letters and mutated amino acids were indicated with underlines

* Responding strengths toward heavy metal(loid) ions were indicated with induction coefficient values and the values under 1.25 were not shown

* The data were obtained by repeating more than 3 times and the standard deviations for induction coefficient values toward each metal(loid) was less than $10 \%$ 
metal ions of the biosensor assay were determined under varying initial $\mathrm{OD}_{600}$ values of the cells.

\section{Plant growth and $\mathrm{Pb}$ (II) treatment}

Arabidopsis thaliana ecotype Columbia (Col-0) was used as a model plant to quantify the $\mathrm{Pb}$ (II) accumulation in plants. Seeds were sterilized using $70 \%$ ethanol and plated on half-strength Murashige and Skoog (1/2 MS) agar media containing $0,250,500$, and $750 \mu \mathrm{M}$ of $\mathrm{Pb}$ (II). The plates were placed in the dark for $3 \mathrm{~d}$ for vernalization, and plants were grown in a growth chamber with a $16 \mathrm{~h} / 8 \mathrm{~h}$ (light/dark) light regime at $23^{\circ} \mathrm{C}$ for $14 \mathrm{~d}$. Images of the plants were taken to verify the inhibitory effects of $\mathrm{Pb}(\mathrm{II})$, and the plants were harvested to quantify the $\mathrm{Pb}(\mathrm{II})$ accumulation.

\section{Quantification of $\mathrm{Pb}$ (II) using biosensors Artificially contaminated water}

To verify the application of $\mathrm{Pb}$ (II) biosensors, artificially contaminated water samples were prepared by spiking metal-free water with $\mathrm{Pb}(\mathrm{II})$. The final concentrations were set to 100, 250, 400, and $500 \mu \mathrm{M}$. Standard curves for the quantification were constructed by fitting induction coefficient values against 0 to $5 \mu \mathrm{M}$ ranges of $\mathrm{Pb}(\mathrm{II})$. The contaminated water samples were applied to biosensor cells after dilution, and the induction coefficient values were determined by using the above-mentioned procedures. Subsequently, the $\mathrm{Pb}(\mathrm{II})$ concentration of the biosensors was calculated using the linear regression fit obtained from the standard curves.

\section{Plants exposed to $\mathrm{Pb}$ (II)}

To quantify the $\mathrm{Pb}$ (II) accumulation in plants, dried plants grown in $\mathrm{Pb}$ (II)-bearing media were grinded and directly applied to $E$. coli cell-based biosensors, that is, plant samples with a dried weight (DW) of $10 \mathrm{mg}$ were added to $2.5 \mathrm{~mL}$ biosensor cells. The induction coefficient values were determined after an incubation of $2 \mathrm{~h}$.
The $\mathrm{Pb}(\mathrm{II})$ accumulation in the plants was quantified by using the linear regression fit obtained from the standard curves. The amount of $\mathrm{Pb}(\mathrm{II})$ in plants was represented as $\mu \mathrm{g} / \mathrm{g}$ DW.

\section{Results \\ Effects of copA and zntA deletion on the metal selectivity of WT ArsR}

In this study, E. coli cell-based biosensors were generated by inserting a pair of plasmids, pArsAp-eGFP and pCDF-ArsR, into E. coli BL21-arsR, -arsR/copA, and -arsR/zntA and by exposing them to $5 \mu \mathrm{M}$ metal(loid) ions, including $\mathrm{As}(\mathrm{III}), \mathrm{Cd}(\mathrm{II}), \mathrm{Ni}(\mathrm{II}), \mathrm{Hg}(\mathrm{II}), \mathrm{Pb}(\mathrm{II})$, $\mathrm{Zn}(\mathrm{II})$, and $\mathrm{Cu}(\mathrm{II})$. Although it was not tested the toxic effects of each metal(loid) on growth of E. coli, some metal(loid)s such as $\mathrm{As}$ (III) and $\mathrm{Hg}$ (II) showed inhibitory effects over $10 \mu \mathrm{M}$ of exposure. In this reason, 5 $\mu \mathrm{M}$ was selected to test selectivity of biosensors to metal(loid)s without inhibition of $E$. coli growth. After an exposure of $2 \mathrm{~h}$, the responses were determined by measuring the expression levels of eGFP. The results were represented as induction coefficient values (Fig. 1). As shown in Fig. 1A, WT ArsR in E. coli-arsR responds to $\mathrm{As}(\mathrm{III})$, which is consistent with previous reports (Yoon et al. 2016a). In the case of E. coli-arsR/copA, the change was insignificant, indicating that the effect of deleting $\operatorname{cop} A$ on the metal specificity is small (Fig. 1B). On the other hand, E. coli cell-based biosensors display a stronger response to $\mathrm{Pb}(\mathrm{II})$ after the deletion of $z n t A$ (Fig. 1C). Note that the gene related to the translocation of divalent metal ions, $z n t A$, which encodes $\mathrm{Zn}(\mathrm{II})$ translocating P-type ATPase, enhances the responses of biosensors to $\mathrm{Pb}(\mathrm{II})$. Although it remains unclear why only the $\mathrm{Pb}$ (II) response is enhanced, the results show that the specificity and selectivity of biosensors could be modulated by interfering with the metal ion homeostasis in E. coli cells (Kang et al. 2018).

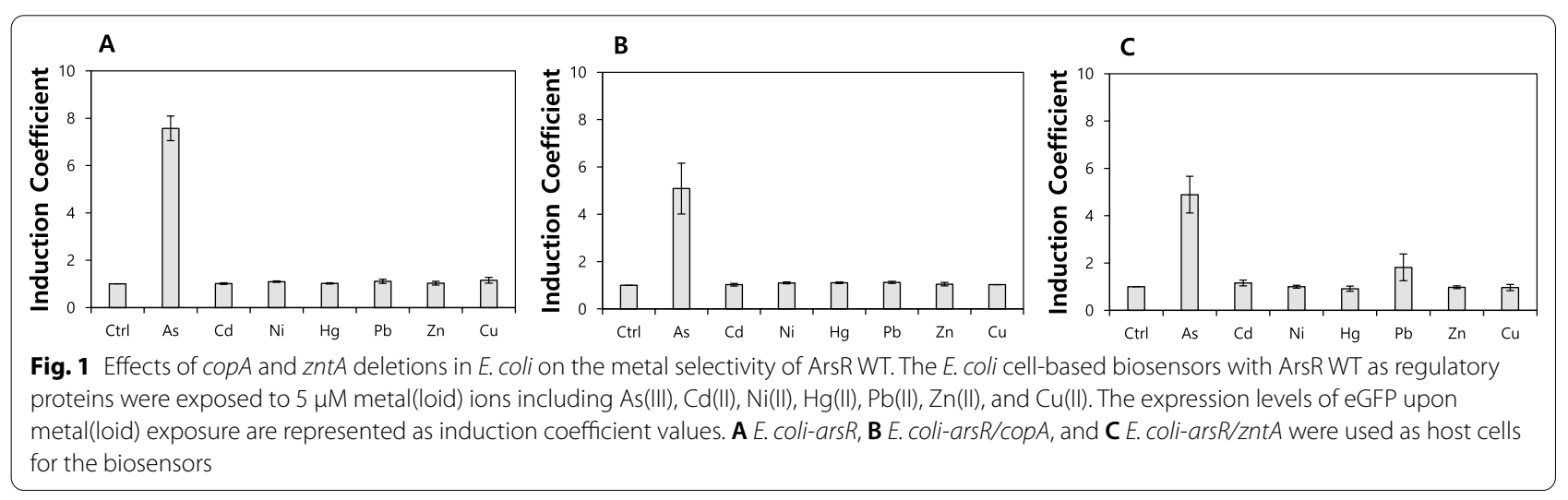




\section{Effects of ArsR engineering on the heavy metal(loid) selectivity}

Biosensors based on $E$. coli-arsR were generated by using engineered ArsRs and pArsAp-eGFPA as sensing and reporter domains, respectively. A series of biosensors was exposed to $5 \mu \mathrm{M}$ heavy metal(loid)s including As(III), $\mathrm{Cd}(\mathrm{II}), \mathrm{Ni}(\mathrm{II}), \mathrm{Hg}(\mathrm{II}), \mathrm{Pb}(\mathrm{II}), \mathrm{Zn}(\mathrm{II})$, and $\mathrm{Cu}(\mathrm{II})$ and the expression of eGFP was measured after an exposure of $2 \mathrm{~h}$. The responses to heavy metal(loid)s were measured as eGFP intensity and converted into induction coefficient values (eGFP intensity with metal exposure/eGFP intensity without exposure). The results are summarized in Table 1. In concordance with our previous report, the biosensor with wild-type ArsR has a strong selectivity and specificity with respect to As(III) (Lee et al. 2020; Yoon et al. 2016a). However, the response to metal ions diminishes and is lost after the deletion of Cys32 or Cys34 with Val33Cys in ArsR, corresponding to ArsR numbers 9 to 16 in Table 1 . They showed induction coefficient values below 1.25 toward tested heavy metal(loid) ions. It was determined that two cysteine residues (32 and 34) are the key amino acids for the recognition of metal ions. On the other hand, engineered ArsR with Cys32/Cys34 or with cysteines on Thr38 instead of Cys37 showed a stronger response to As(III) than WT ArsR without changes in the metal selectivity. Insignificant changes of the metal selectivity were observed for engineered ArsRs with 3 and 4 cysteines, that is, numbers 17 to 24 in Table 1 . Although several ArsRs responded to As(III), the background eGFP intensity increased with and without metal exposure. This implies that the mutations cause conformational changes, which result in inactive ArsR as a repressor for ars-operon. The metal selectivity of the biosensors with ArsR W4, W6, YJ6, and YJ20 are shown in Fig. 2. Although the selected mutants have similar responses to metal(loid) ions as ArsR WT, the response to As(III) decreased and was very weak, less than 1.25 of induction coefficient values toward divalent metal ions.

\section{Effects of genetic engineering of ArsR and host cells on the metal selectivity}

As shown above, the As(III) responses of biosensors decreased due to the engineering of ArsR in E. coli$\operatorname{ars} R$. The effects of metal-exporting channels, that is, $\operatorname{cop} A$ and $z n t A$, which are known to encode metal ion-translocating P-type ATPases, on the metal specificity were evaluated using arsR/copA- and $\operatorname{arsR} / z n t A$ deficient E. coli strains named E.coli-arsR/copA and E. coil-arsR/zntA, respectively. By using those strains as host cells, biosensors were generated by inserting arsAp::egfp and engineered ArsRs; the changes of the metal selectivity were determined under the experimental conditions specified above. Although the induction coefficients slightly change, the $\operatorname{cop} A$

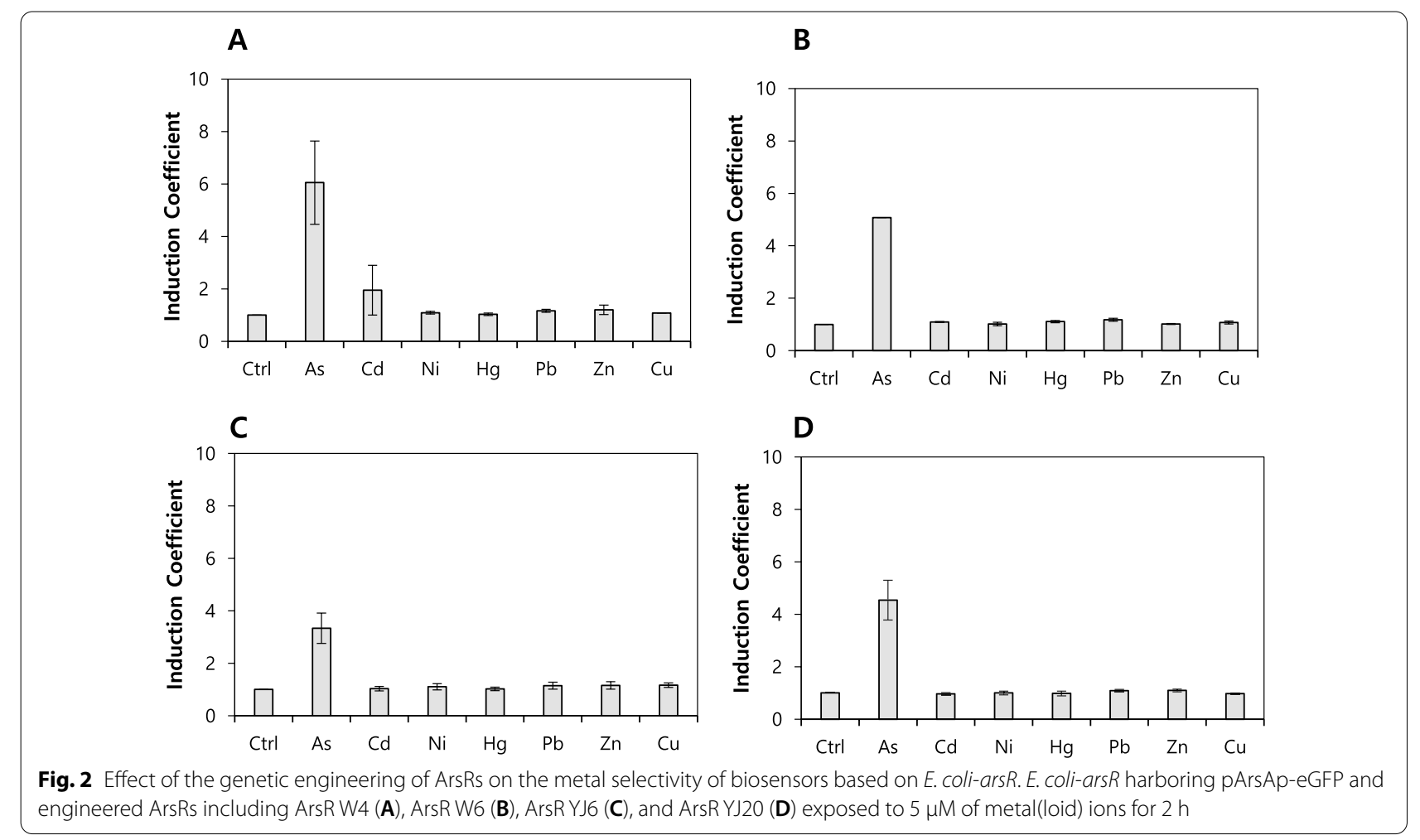


deletion has a significant effect on the metal selectivity compared with that of E. coli-arsR (Table 1).

On the other hand, the biosensors show different responses to divalent metal ions after the deletion of $z n t A$ (Table 1; Fig. 3). First, the responses of the biosensors to divalent metal ions, such as $\mathrm{Cd}(\mathrm{II})$ and $\mathrm{Pb}(\mathrm{II})$, significantly enhanced compared with biosensors based on E. coli-arsR. Second, the responses of engineered ArsR to As(III) decreased compared with WT ArsR (Figs. 1C and 3). In the cases of engineered ArsR W4 and W6, the responses to As(III) and $\mathrm{Pb}(\mathrm{II})$ decreased two- and four-fold, respectively. The ArsR W6 showed a two times stronger response to $\mathrm{Pb}(\mathrm{II})$ compared with $\mathrm{As}(\mathrm{III})$, even if it significantly responded to $\mathrm{Cd}(\mathrm{II})$ (Fig. 3A). The ArsR W4 showed a 1.5 times stronger response to $\mathrm{Pb}$ (II) compared with $\mathrm{As}(\mathrm{III})$ and responded less to $\mathrm{Cd}(\mathrm{II})$ (Fig. 3B). The ArsR YJ6 and YJ20 also showed enhanced responses to $\mathrm{Pb}$ (II) and weakened responses to As(III) (Fig. 3C and D). Based on these results, it can be speculated that the mutation of ArsR changes the target selectivity, and the deletion of $z n t A$ enhances the target specificity based on the accumulation of divalent metal ions in the cells. The results also reveal that $\mathrm{ZntA}$ is related to the translocations of $\mathrm{Zn}(\mathrm{II}), \mathrm{Cd}(\mathrm{II})$, and $\mathrm{Pb}(\mathrm{II})$ ions.

\section{$\mathrm{Pb}$ (II)-sensing E. coli cell-based biosensors}

Although biosensors including a combination of engineered ArsRs and $z n t A$-deficient $E$. coli show broad responses to $\mathrm{As}(\mathrm{III}), \mathrm{Cd}(\mathrm{II})$, and $\mathrm{Pb}(\mathrm{II})$, the selected engineered ArsRs, that is, W6, W4, YJ20, and YJ6, display stronger responses to $\mathrm{Pb}(\mathrm{II})$ than $\mathrm{As}(\mathrm{III})$ (Fig. 3). Therefore, they were further investigated to evaluate their potentials as $\mathrm{Pb}(\mathrm{II})$-sensing biosensors. The biosensors were exposed to a $\mathrm{Pb}$ (II) concentration ranging from 0 to $15 \mu \mathrm{M}$, and the expression of eGFP induced by $\mathrm{Pb}(\mathrm{II})$ was measured after $2 \mathrm{~h}$ at excitation and emission wavelengths of $480 \mathrm{~nm}$ and $510 \mathrm{~nm}$, respectively. The responses were represented as induction coefficient values and the relationship. In E. coli-arsR/zntA, all tested biosensors showed increased signals with increasing concentration (Fig. 4). The ArsRs W6, W4, and YJ20 showed stronger responses to $\mathrm{Pb}$ (II) than ArsR WT, and ArsR YJ6 displayed similar responses. Because they still responded to $\mathrm{As}(\mathrm{III})$ and $\mathrm{Cd}(\mathrm{II})$, they cannot be regarded as $\mathrm{Pb}(\mathrm{II})$ specific biosensors. However, it can be concluded that the $\mathrm{Pb}(\mathrm{II})$ specificity was enhanced while the $\mathrm{As}(\mathrm{III})$ specificity was diminished due to the genetic engineering of both regulatory proteins and host cells.

\section{$\mathrm{Pb}$ quantification in artificially contaminated water}

As described above, in addition to responses to As(III) and $\mathrm{Cd}(\mathrm{II})$, a $\mathrm{Pb}(\mathrm{II})$-sensing capability was observed
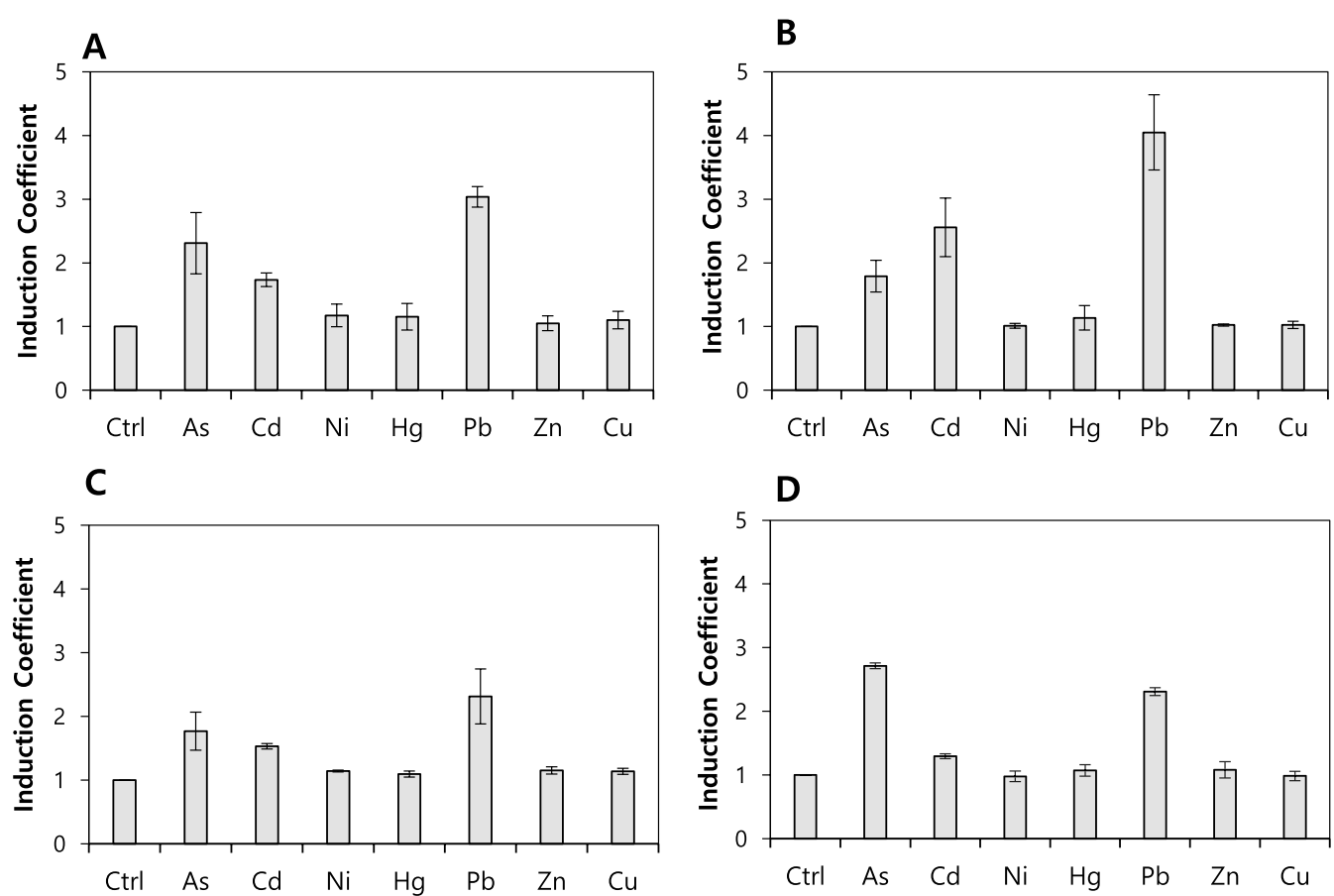

Fig. 3 Metal selectivity of biosensors based on E. coli-arsR/zntA upon engineered ArsRs. E. coli-arsR/ZntA harboring pArsAp-eGFP and engineered ArsRs including ArsR W4 (A), ArsR W6 (B), ArsR YJ6 (C), and ArsR YJ20 (D) exposed to $5 \mu \mathrm{M}$ of metal(loid) ions for $2 \mathrm{~h}$ 

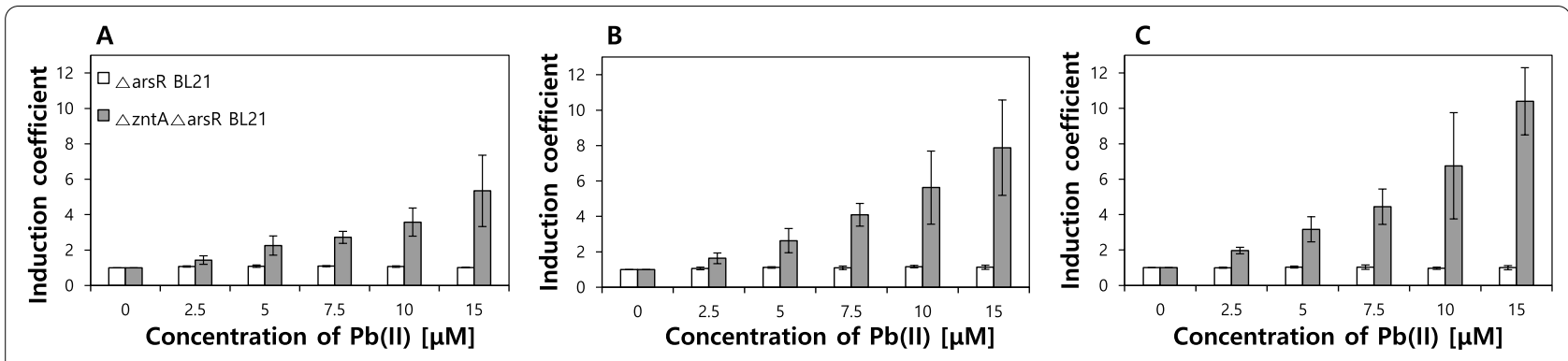

D

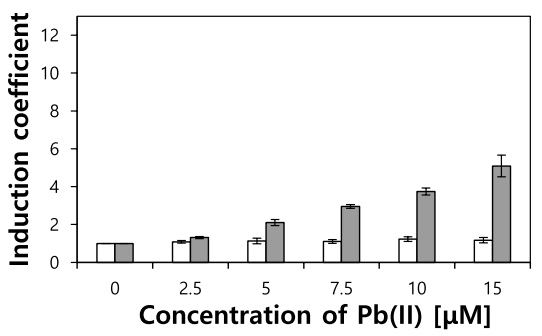

E

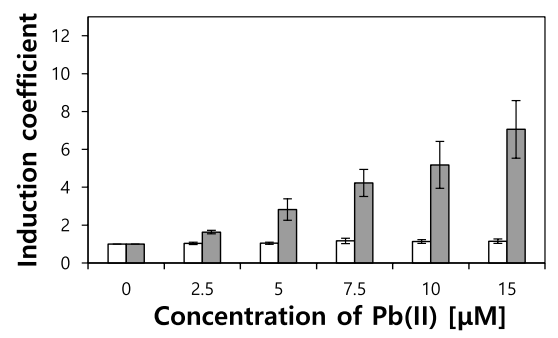

Fig. 4 Concentration-dependent responses of biosensors to $\mathrm{Pb}$ (II). The responses of biosensors using E. coli-arsR and E. coli-arsR/zntA as host cells to $\mathrm{Pb}$ (II) were compared upon regulatory proteins. The concentration of $\mathrm{Pb}(\mathrm{II})$ ranged from 0 to $15 \mu \mathrm{M}$. The responses are indicated as induction coefficient values. A ArsR WT; B ArsR W4; C ArsR W6; D ArsR YJ6; and E ArsR YJ20

by genetic engineering on ArsR and host cells. Thus, it was necessary to evaluate the capabilities of the new $\mathrm{Pb}(\mathrm{II})$-sensing biosensors. With respect to amino acid sequences at the metal binding sites of ArsRs, W4 and W6 have three cysteines, whereas YJ6 and YJ20 have four cysteines (Table 1). Among 4 candidates, biosensors with ArsR W6 and YJ20 were selected for the $\mathrm{Pb}(\mathrm{II})$ quantification because they show stronger $\mathrm{Pb}$ (II) responses based on the presence of three and four cysteines. The performance of the biosensors was analyzed to determine the $\mathrm{Pb}$ (II) concentration in artificially contaminated water samples that were prepared by spiking metal-free water with a known concentration of $\mathrm{Pb}(\mathrm{II})$. The $\mathrm{Pb}$ (II)-spiked water samples were applied to biosensors based on $E$. coli-arsR/zntA with ArsR W6 and ArsR YJ 20 with diverse dilutions. The induction coefficient values of the contaminated water samples were measured, and the concentration was calculated by using the equations obtained from the fitting of the standard curves (Additional file 1: Figure
$\mathrm{S} 1)$. The arbitrary unit of biosensors without $\mathrm{Pb}(\mathrm{II})$ exposure was 300 to 350 , and $0.5 \mu \mathrm{M}$ of $\mathrm{Pb}(\mathrm{II})$ exposure showed about 1.3 times higher. The detection limit was calculated as about 0.15 of induction coefficient based on standard deviation of $0.5 \mu \mathrm{M}$ of $\mathrm{Pb}(\mathrm{II})$ exposure and slope of standard curves. The $\mathrm{Pb}$ (II) concentrations of the artificially contaminated water samples was listed in Table 2 . Compared with originally spiked $\mathrm{Pb}(\mathrm{II})$, the accuracy of the $\mathrm{Pb}(\mathrm{II})$ quantification using both biosensors varied from 95 to $99 \%$ with an error range of $3.5-12.5 \%$.

\section{Quantification of $\mathrm{Pb}$ (II) in plants}

To prepare $\mathrm{Pb}(\mathrm{II})$-bearing plant samples, Arabidopsis thaliana was grown in MS media containing different $\mathrm{Pb}(\mathrm{II})$ concentrations ranging from 0 to $1000 \mu \mathrm{M}$. After an incubation of $14 \mathrm{~d}$ with $16 \mathrm{~h}$ of light/8 h of darkness at $23{ }^{\circ} \mathrm{C}$, images of the plants on each plate were taken, and the plants were harvested and dried. At a $\mathrm{Pb}$ (II) concentration of $250 \mu \mathrm{M}$, seed germination and growth were

Table 2 Quantification of Pb in artificially contaminated water samples using genetically engineered E. coli biosensors

\begin{tabular}{|c|c|c|c|c|}
\hline \multirow{2}{*}{$\begin{array}{l}\text { Spiked conc. } \\
{[\mu \mathrm{M}]}\end{array}$} & \multicolumn{2}{|l|}{ E. coli-arsR/zntA with W6 } & \multicolumn{2}{|c|}{ E. coli-arsR/zntA with YJ20 } \\
\hline & Determined conc. $[\mu \mathrm{M}]$ & $\operatorname{Accuracy}^{+}(\%)$ & Determined conc. $[\mu \mathrm{M}]$ & Accuracy(\%) \\
\hline 100 & $101.3 \pm 11.1$ & 99.0 & $96.3 \pm 10.1$ & 96.3 \\
\hline 250 & $257.9 \pm 14.6$ & 96.9 & $254.3 \pm 31.5$ & 98.3 \\
\hline 400 & $416.5 \pm 31.0$ & 96.0 & $381.4 \pm 38.9$ & 95.2 \\
\hline 500 & $524.8 \pm 39.3$ & 95.3 & $491.6 \pm 18.6$ & 98.3 \\
\hline
\end{tabular}

+ Accuracy was calculated by the coverage of $\mathrm{Pb}$ quantification over originally spiked concentrations 
observed. Above a concentration $750 \mu \mathrm{M}$, germination did not occur (Additional file 1: Figure S2). The inhibition of seed germination and development of lead toxicity have previously been investigated by many research groups (Kabir et al. 2008; Li et al. 2005; Mahmood et al. 2007). Most of the researchers focused on the correlation between the exterior concentration of $\mathrm{Pb}(\mathrm{II})$ and physiological variation of plants. However, the correlation between the $\mathrm{Pb}(\mathrm{II})$ accumulation and physiological changes must be determined.

To determine the $\mathrm{Pb}(\mathrm{II})$ accumulation in the plants, the plant samples were grinded and added to $E$. coli biosensors. After an exposure of $2 \mathrm{~h}$, the expression levels of eGFP were measured, and the amount of accumulated $\mathrm{Pb}$ (II) was calculated by using the equations obtained from the fitting of standard curves. The concentration of $\mathrm{Pb}(\mathrm{II})$ accumulated in plants grown in MS media containing 250 and $500 \mu \mathrm{M} \mathrm{Pb}(\mathrm{II})$ was determined to be $352.22 \pm 114.02$ and $1263.77 \pm 330.13 \mu \mathrm{g} / \mathrm{g}$ DW, respectively (Additional file 1: Table S1). In this regard, it was important to quantify accumulated $\mathrm{Pb}(\mathrm{II})$ to address correlation between adverse effects on the physiological properties of plants and $\mathrm{Pb}$ (II) exposure and to achieve more accurate risk assessments.

\section{Discussion}

Bacterial cell-based biosensors have been widely investigated as alternative quantification tools for environmental monitoring because of their simplicity, low cost, rapid analysis, and bioavailability assessment. Most bacterial cell-based biosensors have common genetic systems consisting of sensing and reporter domains that recognize targets and indicate responses, respectively. The target selectivity of $E$. coli cell-based biosensors can be determined by the selectivity of regulatory proteins in the genetic systems. It has been suggested that the target selectivity can be shifted by modulating the target selectivity of regulatory proteins. In addition, the results of previous studies revealed that the deletion of genes related to endogenous metal ion homeostasis in host cells leads to changes in the target selectivity and specificity (Kim et al. 2020; Yoon et al. 2018).

In this study, $\operatorname{cop} A$ - and $z n t A$-deficient $E$. coli strains were used as host cells for biosensors to verify the effects of genes related to metal homeostasis. Metal ion-translocating P-type ATPases in E. coli, such as CopA and ZntA, are known to control the levels of heavy metal(loid)s in cells (Rensing et al. 1997, 2000; Sharma et al. 2000). As shown in Fig. 1, the As(III) selectivity of the biosensors containing ArsR WT as regulatory proteins changed after the deletion of $z n t A$ while the deletion of $\operatorname{cop} A$ had no effect on the target selectivity. Even if ArsR WT was used as a regulatory protein in each biosensor, $\mathrm{Pb}(\mathrm{II})$ responses were observed after $z n t A$ deletion. It has been suggested that $\mathrm{ZntA}$, that is, $\mathrm{Zn}(\mathrm{II})$-translocating P-type ATPase, is related to $\mathrm{Pb}(\mathrm{II})$ translocation and the deletion of $z n t A$ causes the accumulation of $\mathrm{Pb}$ (II) in the cells. The concentrations of other divalent metal ions, such as $\mathrm{Cd}(\mathrm{II}), \mathrm{Ni}(\mathrm{II})$, and $\mathrm{Zn}(\mathrm{II})$, in the cells might be increased, but they cannot activate ArsR.

As described above, the target selectivity was determined based on the selectivity of regulatory proteins in bacterial cell-based biosensors. Because E. coli cell-based biosensors based on an ars-operon system were regulated by ArsR, the As(III) binding sites were mutated to modulate the metal selectivity. As shown in Table 1, cysteine residues at the binding sites were mutated and relocated to generate engineered ArsRs. The target selectivity of ArsRs was tested in E. coli-arsR, E. coli-arsR/copA, and E. coli-arsR/zntA with pArsAp-eGFP. The ArsRs with both Cys32 and Cys34 show the strongest response to As(III) and the metal response in ArsRs without Cys32 or Cys34 is lost. On the other hand, several engineered ArsRs, that is, numbers 17 to 24 in Table 1, lose their repressor ability, resulting in a strong eGFP expression, even without metal exposure. This could be explained by conformational changes upon mutation, which affected the DNA binding of ArsR. On the other hand, the engineered ArsR W4, W6, YJ6 and YJ20 showed decreased As(III) and increased $\mathrm{Pb}(\mathrm{II})$ responses in $z n t A$-deficient $E$. coli. Additionally, those biosensors showed concentrationdependent responses to $\mathrm{Pb}(\mathrm{II})$ as shown in Fig. 4. So far, lead-responsive operon, $p b r$, was the only genetic system for lead detecting bacterial cell-based biosensors (Jia et al. 2018; Wei et al. 2014). In this regard, it was notable to generate $\mathrm{Pb}(\mathrm{II})$ responding biosensors from arsenicresponsive operon although it was not highly specific to $\mathrm{Pb}(\mathrm{II})$.

Despite many advantageous aspects, bacterial cellbased biosensors were not applied widely to environmental systems. Thus, it was pivotal to elucidate applicable potentials of biosensors for real environmental systems. In this study, new biosensors were used for the quantification of $\mathrm{Pb}(\mathrm{II})$ in artificially contaminated water samples and plants grown in contaminated media. The new biosensors yielded an accuracy above $95 \%$ with respect to the quantification of $\mathrm{Pb}(\mathrm{II})$ in artificially contaminated water samples (Table 2). Although it was not environmental samples collected in the field, it showed the potentials of new biosensors for quantifying $\mathrm{Pb}(\mathrm{II})$ in water systems. In addition, the new $\mathrm{Pb}(\mathrm{II})$ biosensors were applied to plants grown in $\mathrm{Pb}$ (II)-exposed media to quantify the amount of accumulated $\mathrm{Pb}(\mathrm{II})$, which was converted to $\mu \mathrm{g} / \mathrm{g} \mathrm{DW}$. The plants exposed to $\mathrm{Pb}(\mathrm{II})$ concentrations of 250 and $500 \mu \mathrm{M}$ exhibit growth inhibition and contain 352 and 
$1263 \mu \mathrm{g} / \mathrm{g} \mathrm{Pb}$ (II) DW, respectively (Additional file 1: Table S1 and Figure S2). Although the results were not validated based on the comparison with the instrumental analysis in this study, the biosensors are invaluable simple tools that can be used to quantify the $\mathrm{Pb}(\mathrm{II})$ accumulation in plants. The effects of toxic materials on plants have been investigated to determine the correlation between the exterior concentration and physiological properties. However, it was insufficient to assess risks of toxic materials because physiological properties such as intake rates and resistance for toxic materials were varied upon plant species. Therefore, the quantification of the accumulated amount could provide more accurate risk assessment for plants rather than exterior amounts.

In this study, we demonstrated the approaches to modulate target selectivity and specificity of bacterial cell-based biosensors. The metal selectivity of the biosensors was shifted from $\mathrm{As}$ (III) to $\mathrm{Pb}$ (II) by genetic engineering on regulatory protein and the specificity was enhanced by interfering metal homeostasis in host cells. However, it was still necessary to improve performance of biosensors for practical application because of broad selectivity with respect to $\mathrm{Pb}(\mathrm{II}), \mathrm{As}(\mathrm{III})$ and $\mathrm{Cd}(\mathrm{II})$. Even if the applicability of biosensors was evaluated by quantifying $\mathrm{Pb}(\mathrm{II})$ in water and plant samples, the results would be exaggerated by the presence of $\mathrm{As}(\mathrm{III})$ or $\mathrm{Cd}(\mathrm{II})$. In this regard, it was critical to achieve target selectivity and specificity of biosensors to achieve accurate risk assessment. Nonetheless, it would be noticed that the strategy demonstrated here has a great potential with respect to the generation of diverse heavy metal-sensing biosensors based on existing genetic systems and assessment of the risks of heavy metals in environmental systems.

\section{Supplementary Information}

The online version contains supplementary material available at https://doi. org/10.1186/s13568-021-01329-y.

Additional file 1. Additional table and figures.

\section{Acknowledgements}

This study was supported by Konkuk University in 2019 (to Y.Y).

\section{Authors' contributions}

Conceptualization: YY; Methodology: YL and YJ; Investigation and data analysis: YL and YJ; Writing-original draft preparation: YY; Writing-review and editing: YY and GJ. All authors read and approved the final manuscript.

\section{Funding}

Not applicable.

\section{Availability of data and materials}

All data generated or analyzed during this study are included in this manuscript.

\section{Declarations}

Ethics approval and consent to participate

This work did not include studies on human participants or animals.

Consent for publication

All authors agreed to publish this works.

Competing interests

The authors declare no conflict of interest.

\section{Author details}

${ }^{1}$ Department of Environmental Health Science, Konkuk University, 05029 Seoul, Republic of Korea. ${ }^{2}$ School of Biological Sciences and Technology, Chonnam National University, 61186 Gwangju, Republic of Korea.

Received: 22 November 2021 Accepted: 28 November 2021

Published online: 15 December 2021

\section{References}

Baruah S, Dutta J (2009) Nanotechnology applications in pollution sensing and degradation in agriculture: a review. Environ Chem Lett 7(3):191-204

Belkin S (2003) Microbial whole-cell sensing systems of environmental pollutants. Curr Opin Microbiol 6(3):206-212

Busenlehner LS, Pennella MA, Giedroc DP (2003) The SmtB/ArsR family of metalloregulatory transcriptional repressors: structural insights into prokaryotic metal resistance. FEMS Microbiol Rev 27(2-3):131-143

Cerminati S, Soncini FC, Checa SK (2011) Selective detection of gold using genetically engineered bacterial reporters. Biotechnol Bioeng 108(11):2553-2560

Cerminati S, Soncini FC, Checa SK (2015) A sensitive whole-cell biosensor for the simultaneous detection of a broad-spectrum of toxic heavy metal ions. Chem Commun 51(27):5917-5920

Hanrahan G, Patil DG, Wang J (2004) Electrochemical sensors for environmental monitoring: design, development and applications. J Environ Monit 6(8):657-664

Hynninen A, Virta M (2009) Whole-cell bioreporters for the detection of bioavailable metals. Whole Cell Sensing System II:31-63

Ibáñez MM, Checa SK, Soncini FC (2015) A single serine residue determines selectivity to monovalent metal ions in metalloregulators of the MerR family. J Bacteriol 197(9):1606-1613

Jia X, Zhao T, Liu Y, Bu R, Wu K (2018) Gene circuit engineering to improve the performance of a whole-cell lead biosensor. FEMS Microbiol Lett 365(16):fny 157

Kabir M, lqbal MZ, Shafiq M, Farooqi Z (2008) Reduction in germination and seedling growth of Thespesia populnea L., caused by lead and cadmium treatments. Pak J Bot 40(6):2419-2426

Kang Y, Lee W, Jang G, Kim B-G, Yoon Y (2018) Modulating the sensing properties of Escherichia coli-based bioreporters for cadmium and mercury. Appl Microbiol Biotechnol 102(11):4863-4872

Kim H, Jeon Y, Lee W, Jang G, Yoon Y (2020) Shifting the Specificity of E. coli Biosensor from Inorganic Arsenic to Phenylarsine Oxide through Genetic Engineering. Sensors 20(11):3093

Lee W, Kim H, Jang G, Kim B-G, Yoon Y (2020) Antimony sensing whole-cell bioreporters derived from ArsR genetic engineering. Appl Microbiol Biotechnol 104(6):2691-2699

Li W, Khan MA, Yamaguchi S, Kamiya Y (2005) Effects of heavy metals on seed germination and early seedling growth of Arabidopsis thaliana. Plant Growth Regul 46(1):45-50

Mahmood T, Islam K, Muhammad S (2007) Toxic effects of heavy metals on early growth and tolerance of cereal crops. Pak J Bot 39(2):451

Rensing C, Mitra B, Rosen BP (1997) The zntA gene of Escherichia coli encodes a Zn (II)-translocating P-type ATPase. Proc Natl Acad Sci 94(26):14326-14331

Rensing C, Fan B, Sharma R, Mitra B, Rosen BP (2000) CopA: an Escherichia coli Cu (I)-translocating P-type ATPase. Proc Natl Acad Sci 97(2):652-656 
Sharma R, Rensing C, Rosen BP, Mitra B (2000) The ATP hydrolytic activity of purified ZntA, a Pb (II)/Cd (II)/Zn (II)-translocating ATPase from Escherichia coli. J Biol Chem 275(6):3873-3878

Shi W, Wu J, Rosen BP (1994) Identification of a putative metal binding site in a new family of metalloregulatory proteins. J Biol Chem 269(31):19826-19829

Simonds M, Xiao H, Levine SP (1994) Optical remote sensing for air pollutants-review. Am Ind Hyg Assoc J 55(10):953-965

Tecon R, Van der Meer JR (2008) Bacterial biosensors for measuring availability of environmental pollutants. Sensors 8(7):4062-4080

Wei W, Liu X, Sun P, Wang X, Zhu H, Hong M, Mao Z-W, Zhao J (2014) Simple whole-cell biodetection and bioremediation of heavy metals based on an engineered lead-specific operon. Environ Sci Technol 48(6):3363-3371

Yagur-Kroll S, Belkin S (2014) Molecular manipulations for enhancing luminescent bioreporters performance in the detection of toxic chemicals. Bioluminescence 2:137-149

Yoon Y, Kang Y, Chae Y, Kim S, Lee Y, Jeong S-W, An Y-J (2016a) Arsenic bioavailability in soils before and after soil washing: the use of Escherichia coli whole-cell bioreporters. Environ Sci Pollut Res 23(3):2353-2361
Yoon Y, Kim S, Chae Y, Jeong S-W, An Y-J (2016b) Evaluation of bioavailable arsenic and remediation performance using a whole-cell bioreporter. Sci Total Environ 547:125-131

Yoon Y, Kim S, Chae Y, Kang Y, Lee Y, Jeong S-W, An Y-J (2016c) Use of tunable whole-cell bioreporters to assess bioavailable cadmium and remediation performance in soils. PLoS ONE 11(5):e0154506

Yoon Y, Kang Y, Lee W, Oh K-C, Jang G, Kim B-G (2018) Modulating the properties of metal-sensing whole-cell bioreporters by interfering with Escherichia coli metal homeostasis. J Microbiol Biotechnol 28(2):323-329

Zhou W, Saran R, Liu J (2017) Metal sensing by DNA. Chem Rev 117(12):8272-8325

\section{Publisher's Note}

Springer Nature remains neutral with regard to jurisdictional claims in published maps and institutional affiliations.

\section{Submit your manuscript to a SpringerOpen ${ }^{\circ}$ journal and benefit from:}

- Convenient online submission

- Rigorous peer review

- Open access: articles freely available online

- High visibility within the field

- Retaining the copyright to your article

Submit your next manuscript at $\boldsymbol{\nabla}$ springeropen.com 